\title{
Ultimate bearing capacity of existing heavy haul railway concrete simple double-T girder strengthened by anchoring assisted steel beams
}

\author{
Wei Guo Long \\ School of Civil Engineering, \\ Central South University, \\ Changsha, Hunan, P R. China \\ School of Mathematics and Physics, \\ University of South China, \\ Hengyang, Hunan, P R. China \\ E-mail: longwg6767@163.com \\ $\mathrm{Li} \mathrm{Li}$
}

The Third Railway Survey and Design Institute Group

Corporation,

Tianjing, P R. China

E-mail: lili07@tsdig.com

\begin{abstract}
Based on the failure mechanisms analysis of the strengthening method of anchoring assisted steel beams of the existing heavy haul railway concrete simple double-T girders, the plastic ultimate bearing capacity analysis method are presented in this paper, the calculation formula of the strengthening of anchoring assisted steel beams of the concrete simple double- $T$ girders is derived, the ultimate bearing capacity of the heavy-haul railway concrete simple double-T girders is calculated, the field test is carried out to verify the calculation results of theory analysis. The calculation and test results show that the strengthening method of anchoring assisted steel beams can improve the ultimate bearing capacity of the concrete simple double-T girders.
\end{abstract}

Keywords-Heavy-haul railway, concrete simple double-T girder, strengthening of bonding assisted steel beams, ultimate bearing capacity

\section{I . INTRODUCTION}

With China's rapid economic development, China's

\author{
Li Zhong Jiang* \\ School of Civil Engineering, \\ Central South University, \\ National Engineering Laboratory for High Speed Railway \\ Construction \\ Changsha, Hunan, P R. China \\ E-mail: lzhjiang@mail.csu.edu.cn \\ *Corresponding author \\ Ling Kun Chen \\ School of Civil Engineering, \\ Central South University, \\ Changsha, Hunan, P R. China \\ E-mail: lingkunchen08@hotmail.com
}

heavy-haul railway annual volume increases rapidly, the heavy haul train axle load and unit train traction quality are rising, whether the existing heavy-haul railway can meet the requirements of above had become an important topic of departments of the heavy haul railway. The existing heavy haul railway concrete bridge structures due to the low design standard and the use of a certain period and appears of different level of defects and diseases, the bridges may not meet the heavy haul railway transportation needs, therefore, the bridge must been to re-assess, ensure the train through the bridge safely and smoothly. Processing methods of the bridge can not meet the requirement usually has two kinds: one is the demolition of old bridge reconstruction of bridge, construction of new bridge will inevitably affect the normal operation of trains, and the construction period is long, investment is large; another is strengthening on old bridge, its main advantages are less investment, short construction period, and even sometimes also does not affect the normal operation of the railway train. How to reasonable use, correct repair and reinforcement of the existing heavy haul railway bridges is an important task of 
the transport sector, and has great economic benefit and social significance.

Since 1970's, lots of researchers at home and abroad pay much attention to the reinforcement technology of concrete bridges structure strengthened by steel plate or section steel, some research results have achieved, and the reinforcement technology of concrete bridges structure have been widely applied in the actual engineering. Jones and Swamy began to research the concrete girders strengthened by epoxy-bonded steel plates and studied its structural behavior, Basunbul and Sharif studied strengthening of shear damaged RC beams by external bonding of steel plates; In our country, in recent years there are many researchers on concrete girders strengthening conducted a series of studies, is mainly aiming at concrete rectangular or box section beam bottom or compressive region by pasting steel plate or section steel to improve the ultimate bearing capacity of bridge. Because of concrete double $\mathrm{T}$ girders in China's heavy haul railway bridge is widely applied, the research literatures of the concrete simply supported double-T girders reinforcement are less, especially the research literatures of on two lateral side of the concrete simply supported double-T girders anchoring assisted steel beams are less.

Because of the lower edge of flange of the concrete simply supported double-T girders has greater space of using, the strengthening method of anchoring two assisted steel beams in both outside of the existing girders of heavy haul railway bridges is put forward, this method can improve the bearing capacity and the seismic capacity in lateral and vertical of the heavy haul railway bridges. The ultimate bearing capacity of the concrete simply supported double-T girders reinforcement with assisted steel beams were analyzed, the calculation formula of the ultimate bearing capacity of the concrete simply supported double-T girders anchored by the assisted steel beams reinforcement in both outside is deduced, and carried on the test, the test results and the calculation results were compared and analyzed.

\section{II . REINFORCEMENT METHOD OF HEAVY HAUL}

\section{RAILWAY BRIDGES}

The assisted steel beams anchoring is one kind of the section-enlarging reinforcement method, the method can effectively improve the bearing capacity and lateral and vertical stiffness of the heavy haul railway bridges, and it can make full use of the space under the girders flange, the height of assisted steel beams can be maximally increased. The assisted steel beams and simply supported double-T girders fastened by a $\mathrm{T}$ shaped connecting plate with the high strength bolts. The elevation of concrete simple supported double- $\mathrm{T}$ girder of heavy haul railway ridge is shown in Fig.1. The schematic section view of the enforced simply double-T girder is shown in Fig.2. The assisted steel beams and simply supported double-T girders can be connected by two kinds of ways, the enforced simply double-T girder can cooperatively bear the loading. One is casting concrete block between the upper flange of the assisted steel beams and the flange of the concrete double-T girders at a certain distance; another is that the assisted steel beams are connected by a transverse partition plate ( $T$ shaped connecting plate) which can transfer loading effectively.

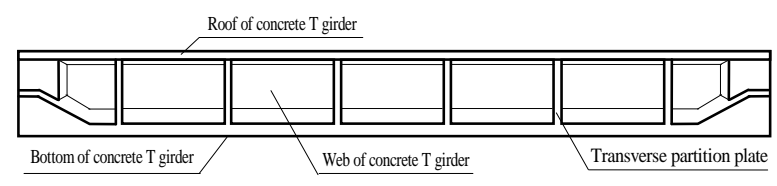

Fig.1 Elevation of concrete $\mathrm{T}$ girder

The main characteristics of the reinforcement method: (1) convenience in construction; (2) various ways can be used to transfer loading, and the integral stress distribution is better; (3) The bearing capacity, the horizontal and vertical seismic capacity of the girders can be greatly improved.

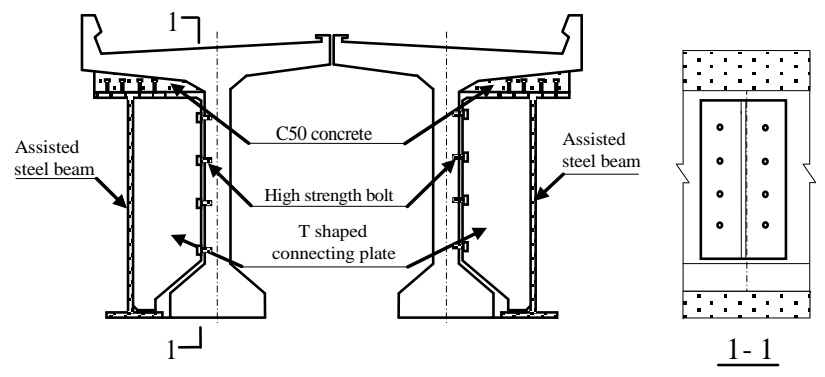

Fig.2 Schematic section view of the enforced simply double-T girder 


\section{FORMULA OF FLEXURAL BEARING CAPACITY}

\section{AFTER STRENGTHENING}

After reinforcement, the section calculation diagram of the simply supported double-T girders is shown in Fig.3. The ultimate bearing capacity and the strength and rigidity of the heavy haul railway bridges are improved, thereby the deformation of heavy haul railway bridges can be reduced The basic assumptions of the reinforced plastic design in the paper are listed as follows:

(1) The assisted steel beams and the concrete double-T girders have no relative sliding; the anchoring connection of the reinforcing girders is full shear connection;

(2) The axial strain of strengthened girders obeys the plane assumption;

(3) When the structure reaches the limit state, compression zone of concrete reaches the compressive design strength value;

(4) The interaction of concrete girders in tension zone is ignored.
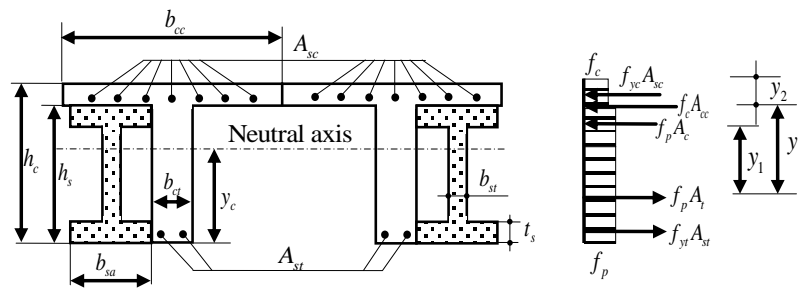

Fig.3 Schematic of reinforced girder normal section and stress

Therefore, according to the force balance, force - balance equation is formulated as

$$
f_{c} A_{c c}+f_{y c} A_{s c}+f_{p} A_{c}=f_{y t} A_{s t}+f_{p} A_{t}
$$

$f_{\mathrm{c}}$ and $f_{\mathrm{p}}$ are separately the compressive strength design value of concrete and strength design value of steel; $f_{\mathrm{yc}}$ and $f_{\mathrm{yt}}$ are respectively the strength design value of the compression and tensile reinforced of the concrete girder; $A_{\mathrm{sc}}$ and $A_{\mathrm{st}}$ are respectively the area of the compression and tensile reinforced of the concrete girder; $A_{\mathrm{c}}$ and $A_{\mathrm{t}}$ are respectively the area of the compression and tensile section of the assisted steel beam; $A_{\mathrm{cc}}$ is the compression area of the concrete girder.

When the concrete reaches the limit state,

$$
F_{c c}=2 f_{c}\left[b_{c c}\left(h_{c}-h_{s}\right)+b_{a}\left(h_{s}-y_{c}\right)\right]
$$

$$
F_{s c}=f_{y c} A_{s c}
$$

$$
F_{s t}=f_{y t} A_{s t}
$$

$$
F_{t}=2 f_{p}\left[b_{s a} t_{s}+b_{s t}\left(y_{c}-t_{s}\right)\right]
$$

$$
F_{s a c}=2 f_{p}\left[b_{s a} t_{s}+b_{s t}\left(h_{s}-y_{c}-t_{s}\right)\right]
$$

where

$$
y_{c}=\frac{E_{c}\left[b_{c c} h_{c}^{2}-\left(b_{c c}-b_{a}\right) h_{s}^{2}\right]+E_{s} h_{s}\left[2 b_{s a} t_{s}+b_{s t}\left(h_{s}-2 t_{s}\right)\right]}{2 E_{c}\left[b_{c c} h_{c}-\left(b_{c c}-b_{a}\right) h_{s}\right]+2 E_{s}\left[2 b_{s a} t_{s}+b_{s t}\left(h_{s}-2 t_{s}\right)\right]}
$$

$E_{\mathrm{c}}$ and $E_{\mathrm{s}}$ are separately the young's modulus of steel and concrete; $y_{\mathrm{c}}$ is the distance of the neutral axis to the lower edge of the concrete girder; $F_{\mathrm{cc}}$ is the bearing maximum pressure of the concrete girder; $F_{\mathrm{sc}}$ is the bearing maximum pressure of the compression steel of the concrete girder; $F_{\mathrm{st}}$ is the bearing maximum tension of tensile steel of the concrete girder; $F_{\mathrm{t}}$ is the bearing maximum tensile force of the assisted steel beam; $F_{s a c}$ is the bearing maximum pressure of the assisted steel beam.

The bending bearing capacity calculation formula of the assisted steel beam reinforcement simply supported double-T girder is

$$
M_{u, p}=F_{c c} y+F_{s c}\left(y_{c}+y_{2}-a_{s}\right)+F_{s a c} y_{1}
$$

where

$$
\begin{gathered}
y_{2}=\frac{b_{c c}\left(h_{c}-h_{s}\right)^{2}+b_{a}\left(h_{s}-y_{c}\right)\left[2 h_{c}-\left(h_{s}+y_{c}\right)\right]}{2\left[b_{c c}\left(h_{c}-h_{s}\right)+b_{a}\left(h_{s}-y_{c}\right)\right]} \\
y_{1}=h_{s}-x_{1}-x_{2} \\
y=h_{c}-y_{2}-x_{2}
\end{gathered}
$$

with 


$$
\begin{aligned}
& x_{1}=\frac{b_{s a} t_{s}^{2}+b_{s t}\left(h_{s}-y_{c}-t_{s}\right)\left(h_{s}-y_{c}+t_{s}\right)}{2\left[b_{s a} t_{s}+b_{s t}\left(h_{s}-y_{c}-t_{s}\right)\right]} \\
& x_{2}=\frac{b_{s a} t_{s}^{2}+b_{s t}\left(y_{c}-t_{s}\right)\left(y_{c}+t_{s}\right)}{2\left[b_{s a} t_{s}+b_{s t}\left(y_{c}-t_{s}\right)\right]}
\end{aligned}
$$

$y$ is the distance of the tensile center of the assisted steel beam to compression center of the concrete girder; $y_{1}$ is the distance of the tensile center to the compression center of the assisted steel beam; $y_{2}$ is the distance of the compression center to upper edge of the concrete girder; $x_{1}$ is the distance of the compression center to the upper edge of the assisted steel beam; $x_{2}$ is the distance of the tensile center to the lower edge of the assisted steel beam; $a_{\mathrm{s}}$ respectively are reinforcement protection layer thickness of the concrete girder.

\section{TEST OF THE FLEXURAL BEARING CAPACITY}

\section{AFTER STRENGTHENING}

\subsection{Making of the testing girders}

According to the actual size of the original girders of the heavy haul railway bridges, all of testing girders are cast by C50 concrete with the scale of 1:20, the length of the girders is $1700 \mathrm{~mm}$; the calculation length is $1600 \mathrm{~mm}$. There are four testing girders specimens (A1, A2, A3, A4) need to be made. A1, A2 as the original girders, A3, A4 are the strengthening girders by the assisted steel beams, the I-shaped assisted steel beams are welded by the steel plates, the thickness of the steel plates are $2 \mathrm{~mm}$, there is the $\mathrm{T}$ shaped steel plate between the assisted steel beams and the concrete double-T girders at intervals of $200 \mathrm{~mm}$, the assisted steel beams is welded to the T-shaped steel plate, and the concrete double-T girders is connected by $4 \Phi 6$ expansion high strength bolts with the T-shaped steel plate. The schematic of testing girders is shown in Fig.4.

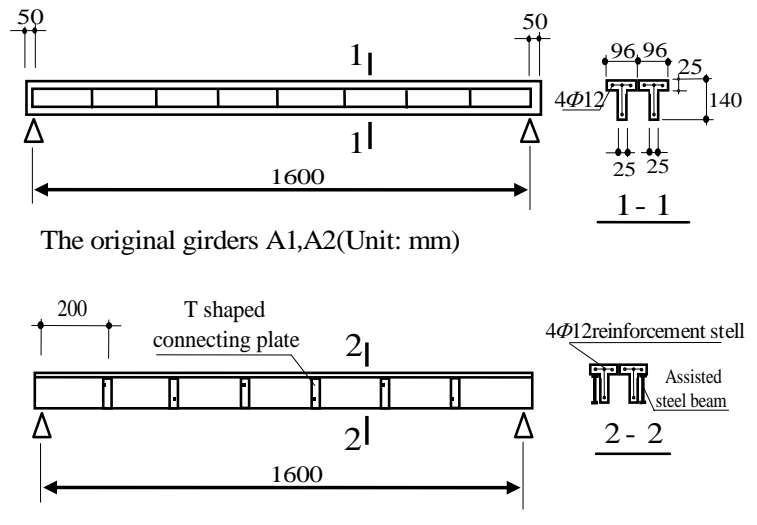

The strengthening girders A3,A4(Unit: mm)

Fig.4 Schematic of testing girders

\subsection{Test plan}

The loading on both ends of the bearing $l / 4$, as shown in figure 5 .

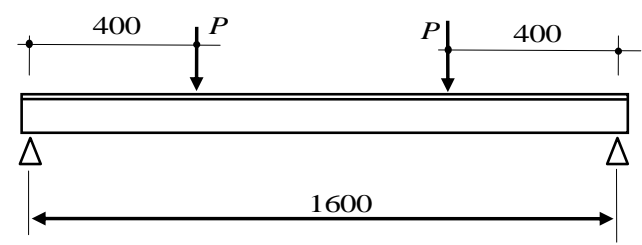

Fig.5 Schematic of load

\subsection{Experiments and results}

A1, A2 are reinforced concrete girders, the failure mode is a typical normal section flexural failure. A3, A4 are the strengthening composite girders by the assisted steel beams, to maintain its stability, the concrete plate are cast between two T girders at intervals of $400 \mathrm{~mm}$, can cooperatively bear the loading. Their failure forms are the same. They appear as elastic deformation before loaded to nearly $60 \%$ of failure loads, when the loading reach $25 \mathrm{kN} \cdot \mathrm{m}$, the surface cracks of the concrete girders are appear, with the load increases, the crack enlarges gradually, but the assisted steel beams and concrete girders there are not appear obvious relative slip, when the loading reach $35 \mathrm{kN} \cdot \mathrm{m}$, the relative slip the assisted steel beams and concrete girders are appear, when the loading reach $38.7 \mathrm{kN} \cdot \mathrm{m}$, the relative slip of the assisted steel beams and concrete girders are about $2 \mathrm{~mm}$, the limit bending moment of this girder is $38.7 \mathrm{kN} \cdot \mathrm{m}$. The test curve of the moment-curvature of the each girder is shown Fig.6. Fig.7 for the loading process of reinforcement beam, Fig. 8 for the damage of original beam, Fig.9 for the 
damage of reinforcement beam.

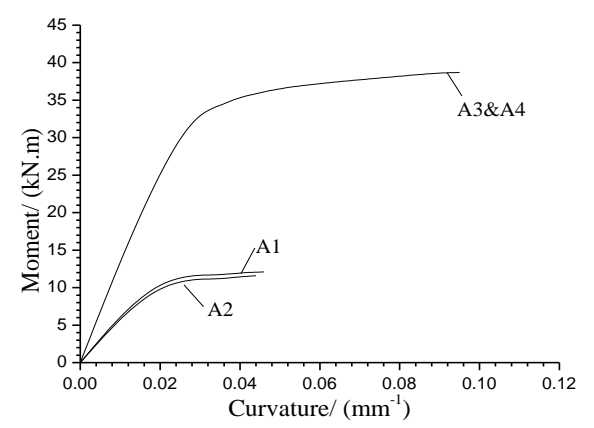

Fig.6 Test curve of moment-curvature of girder

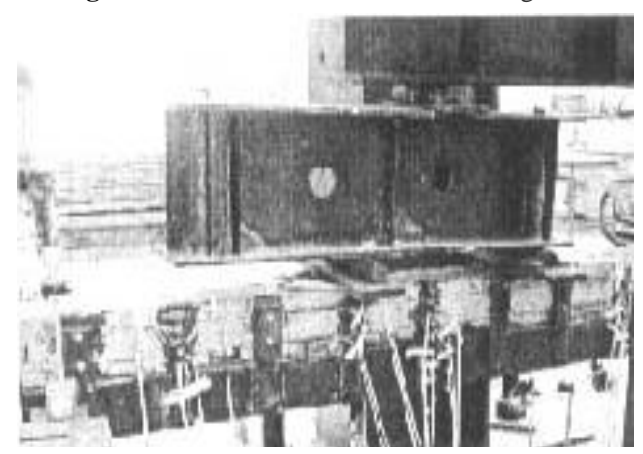

Fig.7 Loading process of reinforcement beam

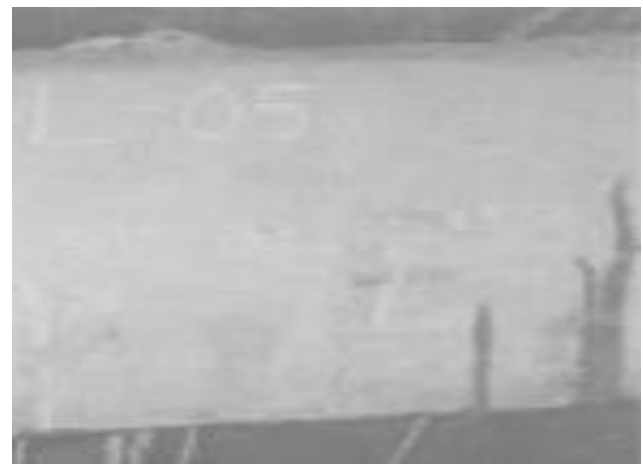

Fig.8 Damage of original beam

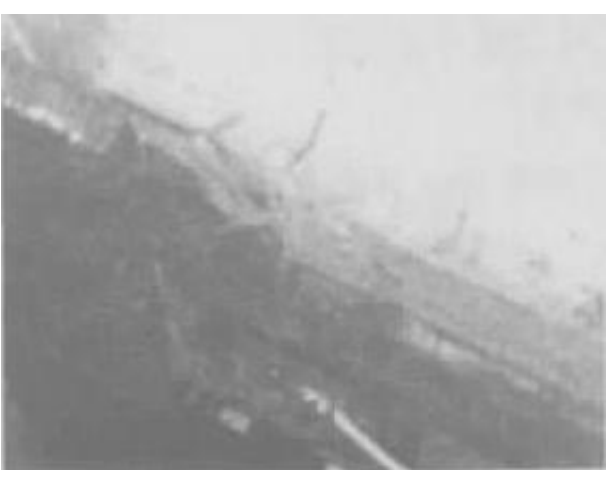

Fig.9 Damage of reinforcement beam

The following conclusions can be drawn: (1) the original girders A1, A2 are damaged early, the girders A3, A4 strengthened by the assisted steel beams are damaged later, it illustrate that the ultimate bending moment of strengthening girders is much larger than of the original girders; (2) there is the smaller relative slip between the assisted steel beams and girders A3, A4, it illustrate that the strengthening girders are shear connection well; (3) all of the girders appear rebound phenomenon after unloading, the strengthened girders are obvious, it show that the elasticity of strengthened girders are better than of the original girders; (4) the strengthened girders have good ductility and strength reserve capacity.

\section{V . ANALYSIS OF FLEXURAL BEARING CAPACITY}

\section{AFTER STRENGTHENING}

The calculation results compared with test results of the flexural bearing capacity of the concrete simply supported double-T girders strengthened by the assisted steel beams by formula 7 in Table. 1 .

Table1 COMPARISONS OF TEST RESULTS AND CALCULATED RESULTS

\begin{tabular}{|c|c|c|c|}
\hline $\begin{array}{l}\text { Flexural } \\
\text { capacity }\end{array}$ & $\begin{array}{l}\text { Test result/ } \\
(\mathbf{k N} \cdot \mathbf{m})\end{array}$ & $\begin{array}{c}\text { Calculation } \\
\text { result/ }(\mathbf{k N} \cdot \mathbf{m})\end{array}$ & $\begin{array}{c}\text { Relative } \\
\text { error/ (\%) }\end{array}$ \\
\hline $\begin{array}{l}\text { The original girder } \\
\text { (A1) }\end{array}$ & 14.1 & 13.7 & 2.84 \\
\hline $\begin{array}{l}\text { The original girder } \\
\qquad(A 2)\end{array}$ & 13.4 & 13.7 & -2.99 \\
\hline $\begin{array}{l}\text { The strengthening } \\
\text { girder }(A 3 \& A 4)\end{array}$ & 38.7 & 37.6 & 2.84 \\
\hline
\end{tabular}

Note: Relative error $=[($ Test results - Calculation result $) /$ Test results $] \times$ $100 \%$

Obviously, the flexural bearing capacity of calculation with the formula 7 is agree excellent with the practical situation; compared with the test result, relative error calculated by the calculation result is smaller. The causes of errors mainly included two aspects: 1) because of the supposed the whole cross section of the assisted steel beams fully step into the plastic stage, and actual condition is not such, when the assisted steel beams is in elastic stage, the reinforcement steel of the tension region of the concrete girders have been rupture, the whole cross section of the assisted steel beams could not be fully into plastic state; 2) the interaction of 
tension zone of the concrete girders is ignored. But because the error is small; therefore, the ultimate bearing capacity of the concrete simply supported double-T girders strengthened by the assisted steel beams calculated by formula 7 is feasible.

\section{CONCLUSION}

Through the theoretical analysis and the test verification, the test results and the calculation results carries on the contrast analysis, the reinforcement method of the simply-supported concrete double-T girders strengthened by the assisted steel beams can be used in the strengthening of heavy haul railway bridges. The following conclusions are drawn:

1) The flexural capacity calculation of the concrete simply supported double-T girders strengthened by the assisted steel beams is still in the exploratory stage, the hypothesis put forward in this paper also waits for further discussion, the flexural capacity calculated by the simplified formula are close to the test results, the error is small, the formula can be applied to practical engineering.

2) By testing, the strengthened girders have good shear performance, ductility, elasticity and strength reserve capacity.

3) The bearing capacity and seismic capacity of horizontal and vertical of the strengthened girders increase.

\section{REFERENCES}

[1] Nie, J. G., and Yu, Z. W. (1999) 'Research and practice of composite steel-concrete beams in China', China Civil Engineering Journal, Vol.32, No.2, pp.3-7.

[2] Mckenna, J. K. M., and Erki, M. A. (1994) 'Strengthening of reinforced concrete flexural members using externally applied steel plates and fiber composite sheets-a survey', Canadian Journal of Civil Engineering, Vol.21, pp.16-24.

[3] Sharif, A., Al-Sulaimani, G. J., Basunbul, I.A., Baluch, M.H., and Husain, M. (1995) 'Strengthening of shear damaged RC beams by external bonding of steel plates', Magazine of Concrete Research, Vol.47No.173, pp.329-334.

[4] Hussain, M., Sharif, A., Basunbul I. A., Baluch, M. H., and AL-Sulaimani, G. J. (1995) 'Flexural Behavior of Precracked Reinforced Concrete Beams Strengthened Externally by Steel
Plates', Structural Journal, Vol.92, No.1, pp.12-23.

[5] Jones, R., Swamy, R. N., and Charif, A. (1988) 'Plate separation and anchorage of reinforced concrete beams strengthened by epoxy-bonded steel plates', The Structural Engineer, Vol.66,No.5, pp.85-94.

[6] Swamy, R. N., Jones, R., and Bloxham, J. W. (1987) 'Structural behavior of reinforced concrete beams strengthened by epoxy-bonded steel plates', The Structural Engineer, Vol.65,No.A(2), pp.59-68.

[7] Yu, Q., Sun, and H. L. (2010) 'Research on the Mechanical properties of concrete beam reinforced by channel steel', Low Temperature Architecture Technology, Vol.139, No.1, pp.43-45.

[8] Tong, G. B., and Lu Y. Y. (2004) 'Analysis of the bearing capacity of RC beams by steel-boned reinforcement', Special Structures, Vol.21, No.1, pp.59-61.

[9] Wang, X. L., and Zhang Y. T. (2006) 'Analysis of the flexural capacity of steel-bonded reinforcement in compressive zone for concrete beams', Journal of Huazhong University of Science and Technology (Urban Science Edition), Vol.23, No.1, pp.93-96.

[10] Sinan Altin, Özgür Anil, and M. Emin Kara. (2005) 'Improving shear capacity of existing RC beams using external bonding of steel plates', Engineering Structures,Vol.27, No.5, pp.781-191.

[11] Roberts, T.M., and Hajkazemi, H. (1989) 'Theoretical study of the behavior of reinforced concrete beams strengthened by externally bonded steel plates', ICE Proceedings, Vol.87, No.1, pp.39-55.

[12] Zhang, S., Raoof, M., and Wood L. A.(1995) 'Prediction of peeling failure of reinforced concrete beams with externally bonded steel plates', Proceedings of the Institution of Civil Engineers. Structures and Buildings, Vol.110, No.3, pp.257-268.

[13] Vilnay, O. (1988) 'The analysis of reinforced concrete beams strengthened by epoxy bonded steel plates', International Journal of Cement Composites and Lightweight Concrete, Vol. 10, No.2, pp.73-78. 